\title{
APPLICATION OF PIEZOCERAMICS IN RELAYS
}

\author{
M. GUNTERSDORFER, P. KLEINSCHMIDT and R. VEITH \\ Siemens Research Laboratories, Munich, Germany
}

(Received February 17, 1975)

\begin{abstract}
For the application of a piezoceramic as a d.c. electromechanical transducer to drive relay contacts the mechanical output energy is the most important feature. The energy has been calculated as a function of the applied electric field strength for longitudinal and transverse operation. For a typical ceramic material maximum values of $53 \mathrm{mWs} / \mathrm{cm}^{3}$ (long.) and $21 \mathrm{mWs} / \mathrm{cm}^{3}$ (trans.) are obtained, taking into account large signal behaviour. Conventional bending elements, which are used to achieve higher deflections at lower voltages, show transformation losses caused by inhomogeneous stress distribution, energy storage in the metal part and inactive bending modes. On the other hand by utilizing the effects of transverse clamping and stiffness compensation, the output energy can be increased by more than one decade as experimentally verified with some special types of highly efficient bending elements. A delayed action relay showing low temperature and shock sensitivity has been tested over more than 10000 switching cycles.
\end{abstract}

\section{INTRODUCTION}

Lead zirconate-titanate piezoceramics have in recent years become a very attractive material for electromechanical transducer applications such as frequency filters, microphones, hydrophones and acoustic pickup systems.

In quasi static systems however there are, except for a laser reflector control device, no commercial applications of piezoceramics. A project of considerable industrial interest, the piezoelectric relay, has been under investigation for some years ${ }^{1,2,3}$ but is still in the experimental stage. The main problem is to realize sufficiently high deflection and contact pressure with low operating voltage. Brauer ${ }^{3}$ has tried to fulfil this requirement by using a piezoelectric bending plate and a hydraulic transformation system acting on a mercury contact sphere moving within a capillary. Although this principle has functioned quite well in laboratory experiments, it has not reached the commercial stage because of its close tolerances. Another proposal has been recorded by Krautwald ${ }^{2}$, who tried to realize large deflections by using a singlelayer meander structure and an interdigitated contact arrangement, but this has likewise not so far overcome the existing difficulties.

In the present paper, bender type piezoelements are described in some detail in order to point out their general possibilities and limitations in relay applications.

\section{THEORETICAL CONSIDERATIONS}

\section{$2.1 \quad$ Piezoelectric Material}

The piezoelectric effect is the property of a material to set up an electric field in response to an applied mechanical strain or stress. Conversely, an applied electric field will produce mechanical strain or stress. Piezoelectric crystals like quartz, Rochelle salt, ammonium dihydrogen phosphate and potassium dihydrogen phosphate (KDP) have long been known. The industrial application of quartz is limited to low energy devices because of its low energy conversion factor. Rochelle salt and KDP-like crystals show relatively high energy conversion factors but low chemical and temperature resistance. These drawbacks can be overcome by modern lead zirconatetitanate ceramics. Table I shows some important electric and mechanical properties of three representative types of piezoceramics.

For relay applications, where the mechanical output energy relative to the applied electric field must be high, it is found that the product of energy conversion-factor and permittivity $k^{2} . \epsilon$ is a figure of merit. With respect to this property material 2 in Table I has the best qualification. The experiments and calculations referred in this paper however correspond to material 1 in Table I, because this material was available in thin sheets. 
TABLE I

Electrical and mechanical properties of some characteristic types of piezoceramics.

\begin{tabular}{|c|c|c|c|c|c|c|}
\hline \multirow[b]{2}{*}{ Property } & \multirow[b]{2}{*}{ Symbol } & \multirow[b]{2}{*}{ Unit } & \multicolumn{2}{|c|}{$\begin{array}{l}\text { Material } 1 \\
\text { H } 42 \\
\text { (Siemens) }\end{array}$} & \multirow{2}{*}{$\begin{array}{l}\text { Material } 2 \\
\text { PXE 51 } \\
\text { (Valvo) } \\
\text { low }\end{array}$} & \multirow{2}{*}{$\begin{array}{l}\text { Material } 3 \\
\text { Sonox } 6 \\
\text { (Rosenthal) } \\
\text { c. }\end{array}$} \\
\hline & & & $\begin{array}{l}\text { low Signal } \\
\text { a.c. }\end{array}$ & $\begin{array}{l}\text { large Signal } \\
\text { d.c. }\end{array}$ & & \\
\hline \multirow[t]{2}{*}{$\begin{array}{l}\text { Piezoelectric strain } \\
\text { constant }\end{array}$} & $\begin{array}{l}d_{33} \\
d_{31}\end{array}$ & $\begin{array}{l}10^{-12} \mathrm{C} / \mathrm{N} \text { or } \\
\mathrm{m} / \mathrm{V}\end{array}$ & $\begin{array}{r}320 \\
-150\end{array}$ & $\begin{array}{r}570 \\
-340\end{array}$ & $\begin{array}{r}480 \\
-234\end{array}$ & $\begin{array}{r}245 \\
-95\end{array}$ \\
\hline & $\begin{array}{l}g_{33} \\
g_{31}\end{array}$ & $\begin{array}{l}10^{-3} \mathrm{Vm} / \mathrm{N} \text { or } \\
\mathrm{m}^{2} / \mathrm{C}\end{array}$ & $\begin{array}{r}25.8 \\
-12.1\end{array}$ & & $\begin{array}{r}19.3 \\
-9.5\end{array}$ & $\begin{array}{r}26.1 \\
-10.1\end{array}$ \\
\hline \multirow[t]{2}{*}{$\begin{array}{l}\text { Piezoelectric stress } \\
\text { constant }\end{array}$} & $\begin{array}{l}e_{33} \\
e_{31} \\
\bar{e}_{33} \\
\bar{e}_{31}\end{array}$ & $\mathrm{C} / \mathrm{m}^{2}$ or $\mathrm{N} / \mathrm{Vm}$ & $\begin{array}{l}12.1 \\
-5.5 \\
17.0 \\
-9.15\end{array}$ & $\begin{array}{r}15.4 \\
-10.3\end{array}$ & $\begin{array}{r}28.1 \\
-17.5 \\
27.0 \\
-16.1\end{array}$ & $\begin{array}{r}21.6 \\
-4.6 \\
17.6 \\
-8.2\end{array}$ \\
\hline & $\begin{array}{l}h_{33} \\
h_{31}\end{array}$ & $10^{8} \mathrm{~V} / \mathrm{m}$ or $\mathrm{N} / \mathrm{mC}$ & $\begin{array}{l}17.7 \\
-8.07\end{array}$ & & $\begin{array}{r}23.5 \\
-14.7\end{array}$ & $\begin{array}{r}39.5 \\
-8.5\end{array}$ \\
\hline Coupling coefficient & $\begin{array}{l}k_{33} \\
k_{31}\end{array}$ & & $\begin{array}{l}0.67 \\
0.34\end{array}$ & & $\begin{array}{l}0.72 \\
0.39\end{array}$ & $\begin{array}{l}0.65 \\
0.30\end{array}$ \\
\hline Relative permittivity & $\begin{array}{l}\epsilon_{33}^{T} \\
\epsilon_{33}^{S}\end{array}$ & & $\begin{array}{r}1400 \\
770\end{array}$ & 4200 & $\begin{array}{l}2800 \\
1350\end{array}$ & $\begin{array}{r}1060 \\
615\end{array}$ \\
\hline Elastic compliance & $\begin{array}{l}s_{11}^{E} \\
s_{11}^{D} \\
s_{33}^{E} \\
D \\
s_{33}\end{array}$ & $10^{-12} \mathrm{~m}^{2} / \mathrm{N}$ & $\begin{array}{c}16.4 \\
14.4 \\
18.8 \\
9.46\end{array}$ & 37 & 17.8 & $\begin{array}{r}11.6 \\
10.6 \\
13.9 \\
8.1\end{array}$ \\
\hline Elastic stiffness & $\begin{array}{l}c_{11}^{E} \\
c_{11}^{D} \\
c_{33}^{E} \\
c_{33}^{D}\end{array}$ & $10^{10} \mathrm{~N} / \mathrm{m}^{2}$ & $\begin{array}{l}12.1 \\
12.6 \\
11.1 \\
14.7\end{array}$ & & 11.7 & 15.0 \\
\hline $\begin{array}{l}\text { Mechanical quality } \\
\text { coefficient }\end{array}$ & $Q$ & & 85 & $\approx 20$ & 50 & 920 \\
\hline $\begin{array}{l}\text { Compressive breaking } \\
\text { strength }\end{array}$ & $T_{c}$ & $10^{8} \mathrm{~N} / \mathrm{m}^{2}$ & 6.0 & 6.0 & 6.0 & 6.0 \\
\hline $\begin{array}{l}\text { Tensile breaking } \\
\text { strength }\end{array}$ & $T_{t}$ & $10^{8} \mathrm{~N} / \mathrm{m}^{2}$ & 0.8 & 0.8 & 0.8 & 0.8 \\
\hline
\end{tabular}

\subsection{Mechanical Output Energy}

\subsubsection{Longitudinal mode For a.c. low signal} applications a piezoelectric material is described by the linear piezoelectric equations of state ${ }^{4}$, which can be written in matrix notation:

$$
\begin{aligned}
& S=s^{E} T+d_{t} E, \\
& D=d T+\epsilon^{T} E,
\end{aligned}
$$

or alternatively, when strain and electric field strength are taken as independent variables:

$$
\begin{aligned}
& T=c^{E} S-e_{t} E, \\
& D=e S+\epsilon^{S} E .
\end{aligned}
$$

Symbols used in these equations are defined in the Appendix. The boundary conditions for the longitudinal mode are: 


$$
T_{1}=T_{2}=D_{1}=D_{2}=E_{1}=E_{2}=0 \text {. }
$$

Assume an electric field strength $E_{3}$ to be applied to a piezoelectric material under constant strain $S_{3}$, Eq. (1) and Eq. (3) give the piezoelectrically produced stress $T_{3}$, given by:

$$
T_{3}=-\frac{d_{33}}{S_{33}^{E}} E_{3}=-\bar{e}_{33} E_{3},
$$

where $\bar{e}_{33}$ is defined as the piezoelectric stress constant $\uparrow$ under the conditions of

$$
T_{1}=T_{2}=0 \text {. }
$$

Relaxing the material under constant electric field strength results in a piezoelectrically produced strain, $S_{3}$, given by:

$$
S_{3}=d_{33} E_{3}=\bar{e}_{33} s_{33}^{E} E_{3} \text {. }
$$

The mechanical energy density $V_{33}$ set free on relaxation is calculated from Eq. (6) and Eq. (8) as:

$$
V_{33}=-1 / 2 S_{3} T_{3}=\frac{1}{2} \cdot \frac{d_{33}^{2}}{s_{33}^{E}} \cdot E_{3}^{2}=1 / 2 \cdot \bar{e}_{33}^{2} s_{33}^{E} E_{3}
$$

Before using this equation for large signal d.c. operation the nonlinearity of the piezoelectric material must be taken into account. For material 1 (Table I), the behaviour was investigated in more detail:

Figures $1 \mathrm{a}$ and $1 \mathrm{~b}$ show the deflection against the applied voltage for longitudinal and transverse action. Figure 2 shows the deflection against the applied force for a piezoelectric bending element. In both cases, applied voltage or applied force, a mechanical hysteresis and a noticable nonlinearity is observed. Regarding the relaxation slopes (II) in Figure 1 and Figure 2 the extreme low and large signal values of $d_{33}, d_{31}$ and $s_{11}^{E}$ are listed in Table I. The relation

$$
\bar{e}=\frac{d}{s}
$$

from Eq. (6) gives the corresponding values of $\bar{e}$. The real mechanical energy set free on relaxation of the

$\dagger \bar{e}_{33}$ must be well distinguished from $e_{33}$, which is defined as the piezoelectric stress constant for the conditions

$$
S_{1}=S_{2}=S_{3}=0 \text {. }
$$

In general $e$ or $\bar{e}$ are better constants than $d$ for the description of the piezoelectric effect, because the physical action of the electric field is to produce mechanical forces, whereas the deflection is the consequence of these forces acting on the elastic properties of the material.

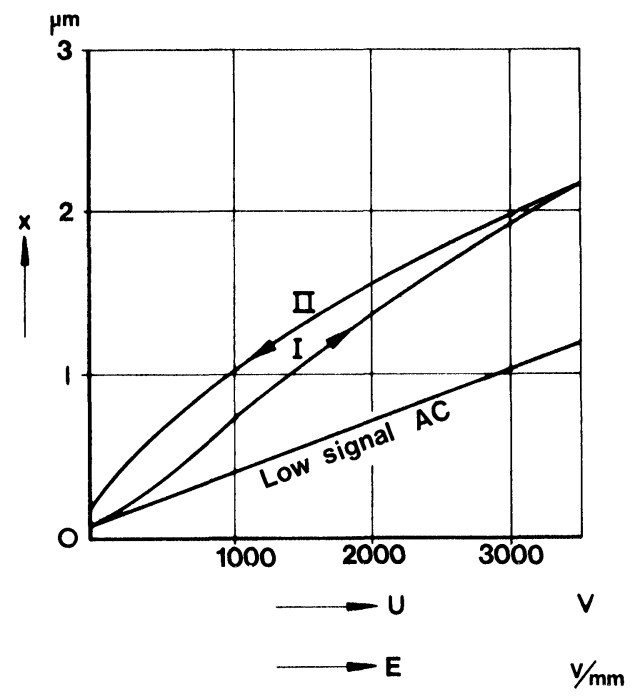

Fig la

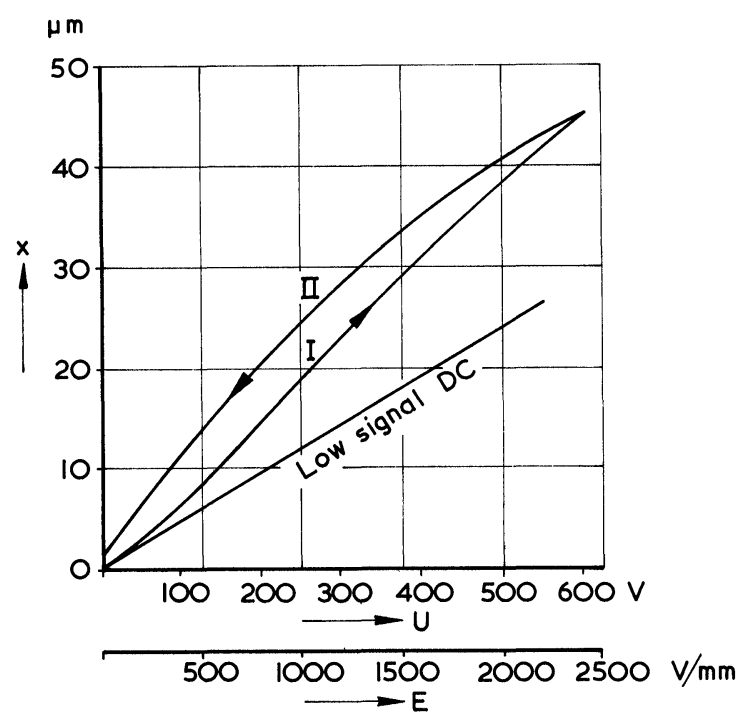

Fig Ib

FIGURE 1 Piezoelectric deflection against applied electric field (material 1)

a) Original plot; longitudinal effect of a $1 \mathrm{~mm}$ thick ceramic disk

b) Transverse effect of an $80 \mathrm{~mm}$ long, $0.25 \mathrm{~mm}$ thick ceramic strip

stressed material is given by

$$
V_{33}=\int_{0}^{S_{\max }} T d S,
$$

regarding the relaxation slope in Figure 2 and this 


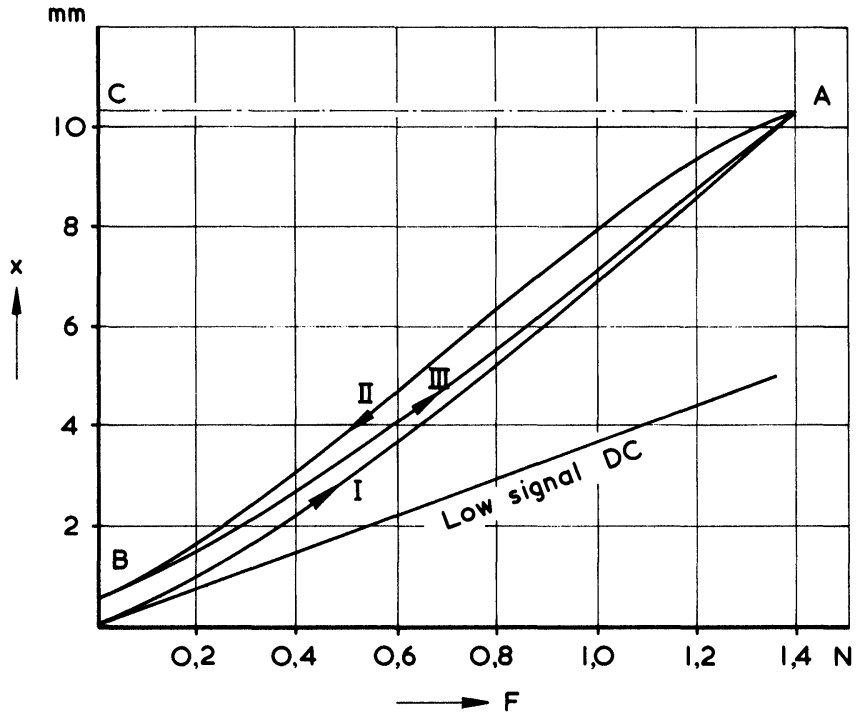

FIGURE 2 Deflection against applied force for a symmetric piezoceramic bending element $l=75 \mathrm{~mm}$, $w=20 \mathrm{~mm}, t=0.7 \mathrm{~mm}$ (material 1$)$

energy is represented by the area $\mathrm{A} \stackrel{\mathrm{II}}{\longrightarrow} \mathrm{B} \rightarrow \mathrm{C}$. The linear approximation calculated in Eq. (9) corresponds to the triangular area $\mathrm{A} \rightarrow \mathrm{B} \rightarrow \mathrm{C}$. As the real relaxation slope shows a point of inflection the linear calculation is a good approximation in spite of the materials large nonlinearity. Material 1 is a highly nonlinear type of piezoceramic, which means that other materials should give further more agreement. For material 1 and a maximum permitted field of $3.5 \mathrm{kV} / \mathrm{mm}$ Eq. (9) gives:

$$
V_{33}=0.053 \mathrm{Ws} / \mathrm{cm}^{3}
$$

the large signal values for $s_{33}^{E}$ and $\bar{e}_{33}$ being taken from Table I.

This result would yield relatively high energy to drive contacts in relays but is extremely difficult to realize on account of the high operating voltage and the small available displacement (given by Eq. (8)).

\subsubsection{Transverse mode To achieve a larger} displacement at lower voltage it is conventional to utilize the transverse piezoelectric effect. A high field is produced by applying the voltage to the opposed surfaces of a thin-sheet piezoelectric element. The boundary conditions for the transverse mode are:

$$
T_{2}=T_{3}=D_{1}=D_{2}=E_{1}=E_{2}=0
$$

Similarly to the longitudinal mode we get in linear approximation

$$
\begin{aligned}
& T_{1}=-\frac{d_{31}}{s_{11}^{E}} \cdot E_{3}=-\bar{e}_{31} E_{3} \\
& S_{1}=d_{31} E_{3}=\bar{e}_{31} s_{11}^{E} E_{3}
\end{aligned}
$$

and

$$
V_{31}=-1 / 2 S_{1} T_{1}=\frac{1}{2} \cdot \frac{d_{31}^{2}}{s_{11}^{E}} \cdot E_{3}^{2}=1 / 2 \cdot \bar{e}_{31}^{2} s_{11}^{E} E_{3}
$$

where $\bar{e}_{31}$ is defined as the piezoelectric stress constant for the conditions

$$
T_{2}=T_{3}=0 \text {. }
$$

Compared with $0.053 \mathrm{Ws} / \mathrm{cm}^{3}$ for longitudinal operation, we obtain for transverse operation and an electric field strength of $3.5 \mathrm{kV} / \mathrm{mm}$

$$
V_{31}=0.021 \mathrm{Ws} / \mathrm{cm}^{3} \text {. }
$$

\subsubsection{Bending mode For further enhancement} of the piezoelectrically produced displacement it is

\section{TABLE II}

Some special types of bending elements and their energy output relative to non-bending transverse operation (after Eq. (16)).

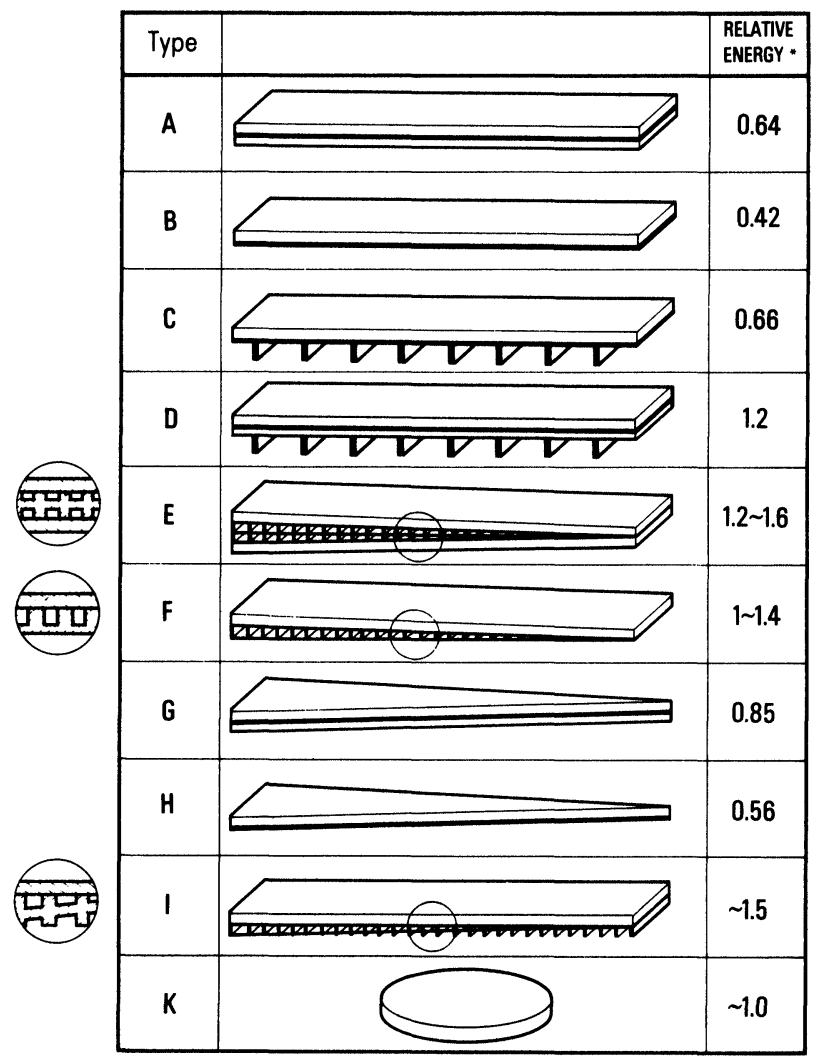


conventional to combine the transverse mode with a bending mode.

Figure 3a shows a simple symmetric type bending element consisting of two poled (indicated by arrows) ceramic layers $C_{1}$ and $C_{2}$ fixed together and with one end clamped in a support $S$. This element is unable to produce the full mechanical energy given by Eq. (16) on account of certain reducing factors. On the other hand special modifications of the bending element can increase the output energy. All these effects will be considered in detail now.

Thickness effect Applying a voltage to terminals 1 and 2 (Figure $3 \mathrm{a}$ ) produces in the cross section of the ceramic a constant elastic stress

$$
T_{0}=\bar{e}_{31} E_{3},
$$

which changes its sign at $z=0$ as shown in Figure $3 b$ slope 1 . This mechanical stress results in a circular bending of the element. After bending, the function of the stress over the ceramic cross section must be linear and is determined by the condition of the zero integral bending moment

$$
\int_{0}^{z_{0}} T(z) z d z=0
$$

and the boundary condition

$$
T(0)= \pm T_{0} \text {. }
$$

These conditions lead to the stress function

$$
T(z)=T\left(1-\frac{3 z}{2 z_{0}}\right)
$$

which is inserted in Figure $3 \mathrm{~b}$ as slope 2.

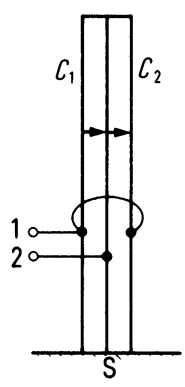

a

FIGURE 3 Piezoelectric bending element

a) Working principle

b) Variation of mechanical stress over the crossection (1) before bending

(2) after bending
The specific output energy is given by

$$
V=\frac{s_{11}^{E}}{2 z_{0}} \cdot \int_{0}^{z_{0}}\left[T_{0}-T(z)\right]^{2} d z .
$$

Eq. (22) in Eq. (23) yields

$$
V=\frac{s_{11}^{E}}{2 z_{0}} \cdot \int_{0}^{z_{0}}\left(\frac{3 T_{0} z}{2 z_{0}}\right)^{2} d z
$$

and with Eq. (19)

$$
V=\frac{3}{8} \bar{e}_{31}^{2} s_{11}^{E} E_{3}^{2} .
$$

Compared with Eq. (16) this represents $75 \%$ of the energy achieved in non-bending transverse operation.

Inserting an ideal spacer, i.e. a spacer without bending stiffness and with infinite shear stiffness, between the two ceramic layers would increase the output energy by up to $100 \%$ with infinite spacer thickness. Figure 4 shows the essential structure of

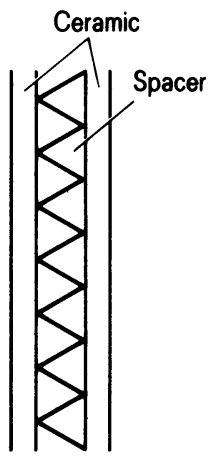

FIGURE 4 Bending element with ideal spacer

an ideal spacer consisting of a zig-zag folded metal foil. Calculations by Lucas ${ }^{5}$ shown in Figure 5a give the output energy as a function of the thickness and elastic stiffness of real spacers. For a steel spacer $\left(s_{1} / s_{2}=6\right)$ the maximum energy (85\% compared with Eq. (16)) is reached when the spacer has $20 \%$ of the thickness of the ceramic layer.

Longitudinal storage Similar calculations are possible for asymmetric elements consisting of a single ceramic strip affixed to a metal strip, but in that case there is a further loss of energy due to longitudinally stored elastic energy within the metal part. Figure $5 \mathrm{~b}$ shows the results ${ }^{5}$ giving the output energy as a function of the thickness and elastic stiffness of the used metal. For steel $\left(s_{1} / s_{2}=6\right)$ the maximum output energy ( $56 \%$ of the value given by Eq. (16)) is 

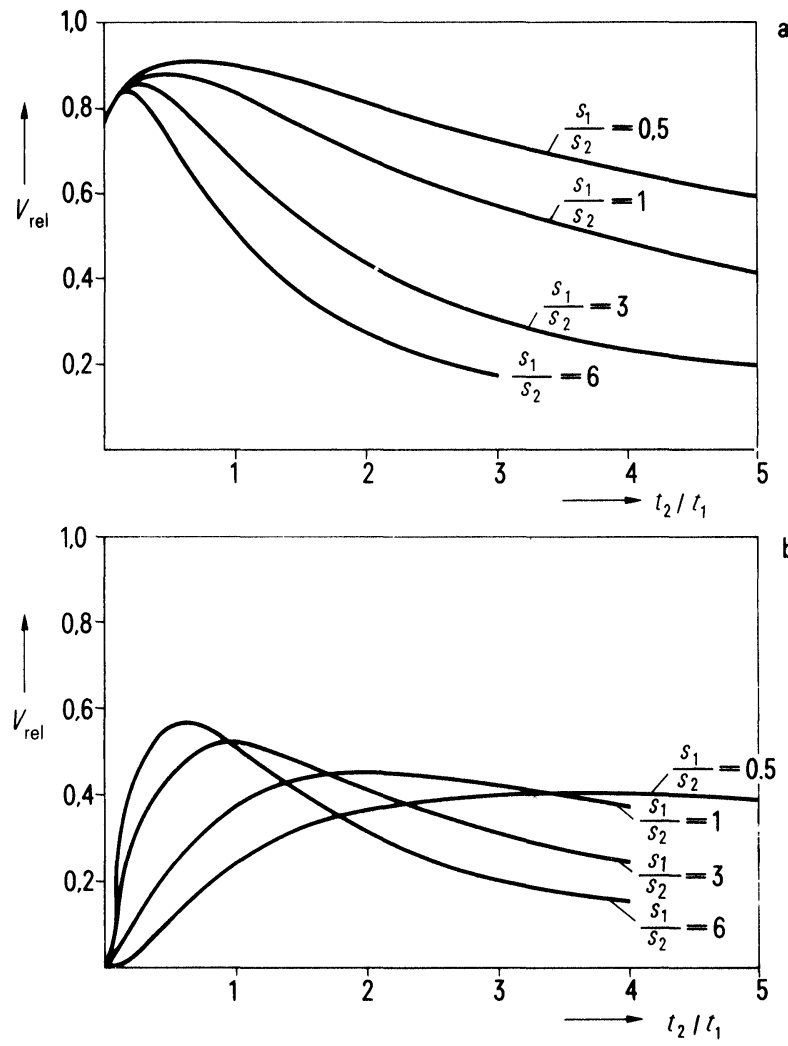

FIGURE 5 Output energy of bending elements relative to nonbending transverse operation (from Eq. (9)) as a function of the ratio of the metal thickness, $t_{2}$, to the ceramic thickness $t_{1}$ neglecting inactive bending modes. Parameter: Ceramic compliance $s_{1}$ relative to the metal compliance $s_{2}$

a) Symmetric element (type A, table II)

b) Asymmetric element (type B, table II) (calculated by Lucas $^{5}$ )

reached when the metal part has $70 \%$ of the thickness of the ceramic layer.

Transverse clamping The transverse piezoelectric effect used in bending elements is given as the deflection in $x$ direction relative to an applied field in $z$ direction, without stress in $y$ and $z$ direction. If the material is clamped in $y$ direction the effect will be increased by Poisson's ratio:

$$
d_{31}^{\prime}=(1+\mu) d_{31}
$$

The compliance $s_{11}^{E}$ is also modified into

$$
s_{11}^{E \prime}=\left(1-\mu^{2}\right) s_{11}^{E} \text {. }
$$

Together with the relation from Eq. (14)

$$
\bar{e}_{31}=\frac{d_{31}}{s_{11}^{E}}
$$

we get

$$
\bar{e}_{31}^{\prime}=\frac{1}{1-\mu} \cdot \bar{e}_{31} .
$$

Taking $\mu=0.3$ Eq. (16) yields

$$
V_{31}^{\prime}=1.85 V_{31}
$$

This effect is utilized in the elements C and D

(Table II) using stiffening fins and in the elements $\mathrm{E}$, $\mathrm{F}$ and I using profiled metals. Full transverse clamping is realized for symmetric elements; in asymmetric elements there is an efficiency loss due to elastic storage in the metal.

Inactive bending modes In the simple arrangement shown in Figure 6 where the bending strip is clamped

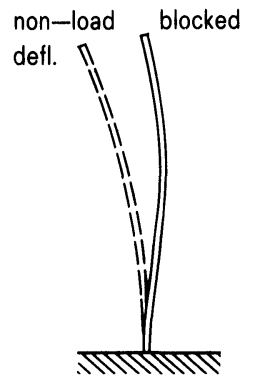

FIGURE 6 Inactive bending mode

at one end and mechanical energy output appears at the free end, it is not possible to couple out the full deformation energy produced by the bending element (given in Figure 5). This may be explained as follows: If the free end is fixed in its zero voltage state and voltage is applied to the element, there is no mechanical energy output but the element undergoes the type of deformation shown in Figure 6. The mechanical energy of this deformation is converted into heat by a damped oscillation and thereby lost. The loss has been calculated to be $25 \%$. This effect can be avoided by varying the cross section of the bending element over the length, so that the elastic stress produced in the ceramic material by the force applied to the free end is constant over the length. This condition is satisfied in practice by a triangular element (types $\mathrm{G}$ and $\mathrm{H}$ in Table II) or a rectangular element varying linearly in thickness over its length (types $\mathrm{E}$, $\mathrm{F}$ and $\mathrm{I}$ in Table II).

Stiffness compensation Eq.'s (9) and (16) define the mechanical output energies of a piezoelectric 
element used in the longitudinal and transverse mode. In both cases the energy is proportional to the mechanical compliance $s$. Increasing the compliance of the piezoelectric material should increase the output energy. A mechanism of this kind is used in conventional bimetallic elements, where the difference between the thermal expansion coefficients of two metals is used to produce mechanical energy. It is established practice in this case to compensate the bending stiffness by springs, usually Omega-shaped springs, as shown in Figure 7. In a limited region of deflection an Omega-spring in this way exhibits a negative stiffness with respect to the motion of the bending element. For a piezoelectric bending strip, the output energy given by Eq. (25) would increase infinitely if the Omega-spring could exactly compensate the stiffness of the element $\left(s_{11}^{E} \rightarrow \infty\right)$. A limit is set by the mechanical strength of the piezoelectric material and by mechanical losses. Neglecting mechanical losses means that, in the case of stiffness compensation, the full piezoelectric force would be available over the full deflection range limited only by the mechanical strength, whereas in the absence of compensation the full piezoelectric force would be available only in the undeflected state.

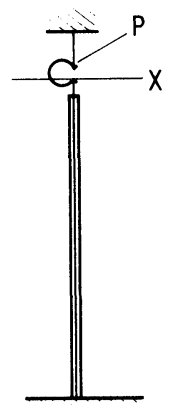

FIGURE 7 Bending element with stiffness compensation by an Omega-shaped spring

To estimate the energy gain obtained by a compensation mechanism, the simple case of the longitudinal mode is considered. Without compensation the energy output is given by Eq. (9) and with ideal compensation by

$$
V_{33}^{\prime \prime}=S_{3_{\max }} \cdot T_{3_{\mathrm{p}}}
$$

where $S_{3_{\max }}$ is the maximum permissible deformation limited by the breaking strength and $T_{3_{\mathrm{p}}}$ the piezoelectric force. Substituting $S_{3_{\max }}$ by $T_{3_{\max }} \cdot s_{33}^{E}$ in
Eq. (31) we obtain

$$
V_{33}^{\prime \prime}=T_{3_{p}} \cdot T_{3_{\max }} \cdot s_{33}^{E}=\bar{e}_{33} s_{33}^{E} E_{3} T_{3_{\max }} .
$$

A similar consideration gives

$$
V_{31}^{\prime \prime}=\bar{e}_{31} s_{11}^{E} E_{3} T_{1 \max }
$$

for the transverse mode.

Comparing these results with Eq. (9) and Eq. (16) the upper limit of the possible energy gain for the longitudinal and the transverse mode is given by

$$
\alpha_{33_{\max }}=\frac{V_{33}^{\prime \prime}}{V_{33}}=\frac{2 T_{3_{\max }}}{\bar{e}_{33} E_{3}} .
$$

and

$$
\alpha_{31 \text { max }}=\frac{V_{31}^{\prime \prime}}{V_{31}}=\frac{2 T_{1_{\max }}}{\bar{e}_{31} E_{3}}
$$

In the presence of elastic hysteresis the stiffness of a piezoelectric material cannot be compensated completely. A reasonable stiffness compensation for this case is shown in Figure 8. Moving an element
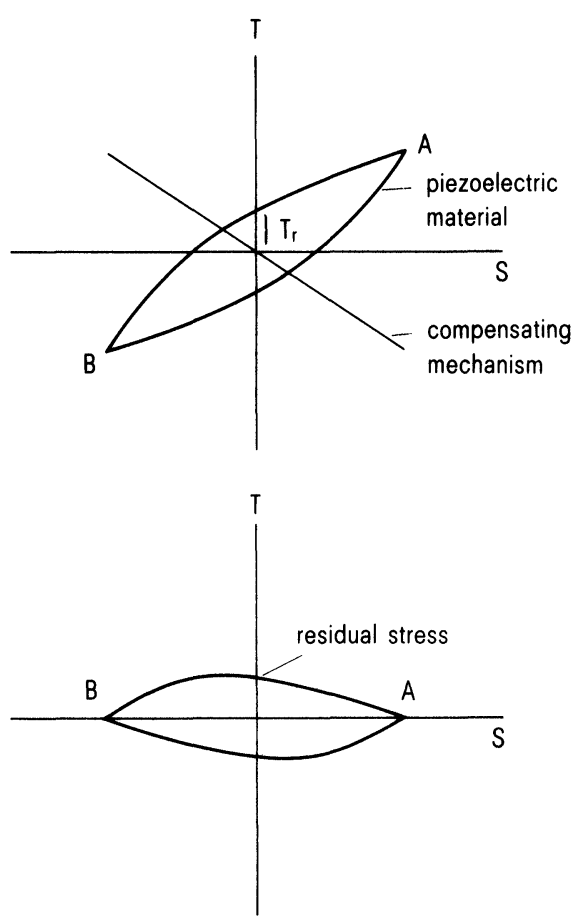

FIGURE 8 Stiffness compensation in the presence of elastic hysteresis 
from position $A$ to position $B$ requires an external force acting against the residual restoring forces of the element. The maximum restoring force $T_{r}$ is approximately equal to one half the width of the hysteresis loop, which in turn depends on the mechanical quality factor of the piezoelectric material and the elastic stress amplitude. An approximate calculation for the longitudinal mode gives

$$
T_{r}=\frac{\pi T_{A}}{2 Q} \approx \frac{\pi S_{A}}{2 Q s^{E}} .
$$

The operation of a piezoelectric relay requires that the restoring stress is smaller than the piezoelectrically generated stress:

$$
T_{r}<T_{p} .
$$

Taking into account Eq. (6) and Eq. (34) this condition means that for a given electric field strength the strain is limited to a certain value

$$
S_{A}<\frac{2 Q d_{33} E_{3}}{\pi} \text {. }
$$

With this value an upper limit for the energy output in the presence of elastic hysteresis is obtained

$$
V_{32}^{\prime \prime \prime}=-\frac{1}{2} S_{A} T_{p}
$$

or inserting Eq. (6) and Eq. (38)

$$
V_{33}^{\prime \prime \prime}=\frac{Q}{\pi} \cdot \frac{d_{33}^{2}}{s_{33}^{E}} \cdot E_{3}^{2}=\frac{Q}{\pi} \cdot \bar{e}_{33}^{2} s_{33}^{E} E_{3}^{2} .
$$

With large electric fields and high mechanical $Q$ the strain may be limited by the tensile stress of the piezoelectric material rather than by residual restoring forces. In this case the energy output approaches the value given by Eq. (32). Comparison of Eq. (40) with Eq. (9) shows the energy gain to be given by

$$
\alpha_{33}=\frac{2 Q}{\pi} \text {. }
$$

Similar calculations are valid for the transverse mode yielding:

$$
V_{31}^{\prime \prime \prime}=\frac{Q}{\pi} \bar{e}_{31}^{2} s_{11}^{E} E_{3}^{2}
$$

and

$$
\alpha_{31}=\frac{2 Q}{\pi} .
$$

Table III shows the quality factor of material 1 as a function of the mechanical stress amplitude. The
TABLE III

Material 1: Mechanical quality factor as a function of stress and the corresponding electric field for the case of stiffness compensation.

\begin{tabular}{lll}
\hline $\begin{array}{l}\text { Mechanical } \\
\text { stress } \\
\left(\times 10^{5} \mathrm{~N} / \mathrm{m}^{2}\right)\end{array}$ & $\begin{array}{l}\text { Quality } \\
\text { factor }\end{array}$ & $\begin{array}{l}\text { Corresponding } \\
\text { electric field } \\
\text { strength }(\mathrm{V} / \mathrm{m})\end{array}$ \\
\hline 2.52 & 85 & $525^{\mathrm{a}}$ \\
5.13 & 57 & $1580^{\mathrm{a}}$ \\
12.5 & 42 & $5250^{\mathrm{a}}$ \\
500 & 21 & $420 \cdot 10^{3 \mathrm{~b}}$ \\
800 & 21 & $670 \cdot 10^{3 \mathrm{~b}}$ \\
\hline
\end{tabular}

${ }^{\text {a}}$ From resonant frequency band width measurements carried out by Dänel (unpublished).

bFrom own deflection vs. force measurements (as shown in Figure 2).

values of the electric field strength given in Table III are the product of the field given by the equation for the piezoelectric stress

$$
T_{p}=\bar{e} E
$$

and the gain factor given by Eq. (41) and Eq. (43). For material 1 Figure 9 shows the output energy

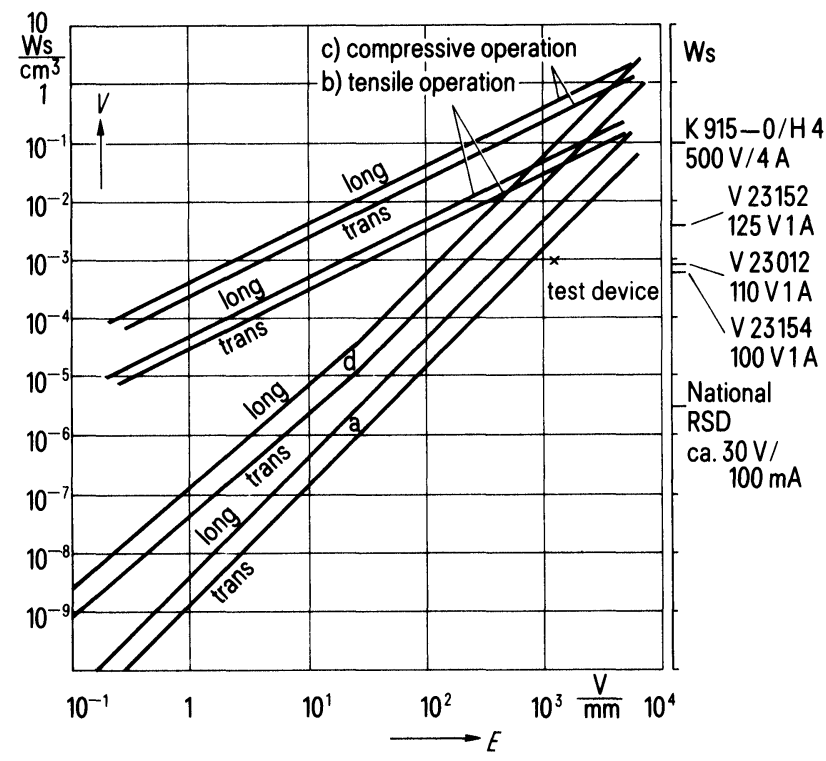

FIGURE 9 Calculated specific output energy as a function of electric field for non-bending longitudinal and transverse operation (material 1)

a) without stiffness compensation, Eq.'s (9) and (16)

b), c) with stiffness compensation, without elastic hysteresis, Eq.'s (32) and (33)

d) with stiffness compensation and elastic hysteresis, Eq.'s (40) and (42). 
attainable in direct operation plotted against the applied field strength for various modes of operation. In principle there is a square-law field dependence in the absence of stiffness compensation and a linear field dependence in the case of full compensation. Up to about $1000 \mathrm{~V} / \mathrm{mm}$ the output energy is limited solely by the mechanical losses of the material. The improvement in mechanical quality under low stress is effective only with very low field strengths of below $10 \mathrm{~V} / \mathrm{mm}$.

\section{TECHNOLOGICAL ASPECTS}

\subsection{Some Special Types of Bending Elements}

For experimental investigations, bending elements of $77 \mathrm{~mm}$ active length and $20 \mathrm{~mm}$ width, consisting of a metal strip covered with one or two $0.3 \mathrm{~mm}$ thick sheets of piezoceramic, were used. Electrical contact between the silvered ceramic and the metal was secured by scribing the metal surface before gluing. The ceramic sheets were fabricated by sintering stacks of "doctorbladed", bandcast layers.

In symmetric elements one of the two ceramic layers is exposed to a depolarizing field and the operating voltage is limited to about $100 \mathrm{~V}$.

In an asymmetric element, where the operating field is directed only in the polarizing direction, $500 \mathrm{~V}$ can be applied. To avoid thermal bending the metal part of asymmetric elements is Vacon 70, a special $\mathrm{Ni}-\mathrm{Co}-\mathrm{Fe}$-alloy. Because of the square-law dependence of the mechanical energy on the applied field Eq. (9), higher output energy is obtained with asymmetric than with symmetric elements. Another special advantage of the asymmetric element is the fact, that piezo-materials of highest $k^{2} \epsilon$ parameters, which are also readily depoled, might be used.

Table II shows the expected theoretical values of the output energy for certain different types of bending elements. Three types of asymmetric elements, denoted $\mathrm{B}, \mathrm{C}$ and $\mathrm{F}$ were investigated

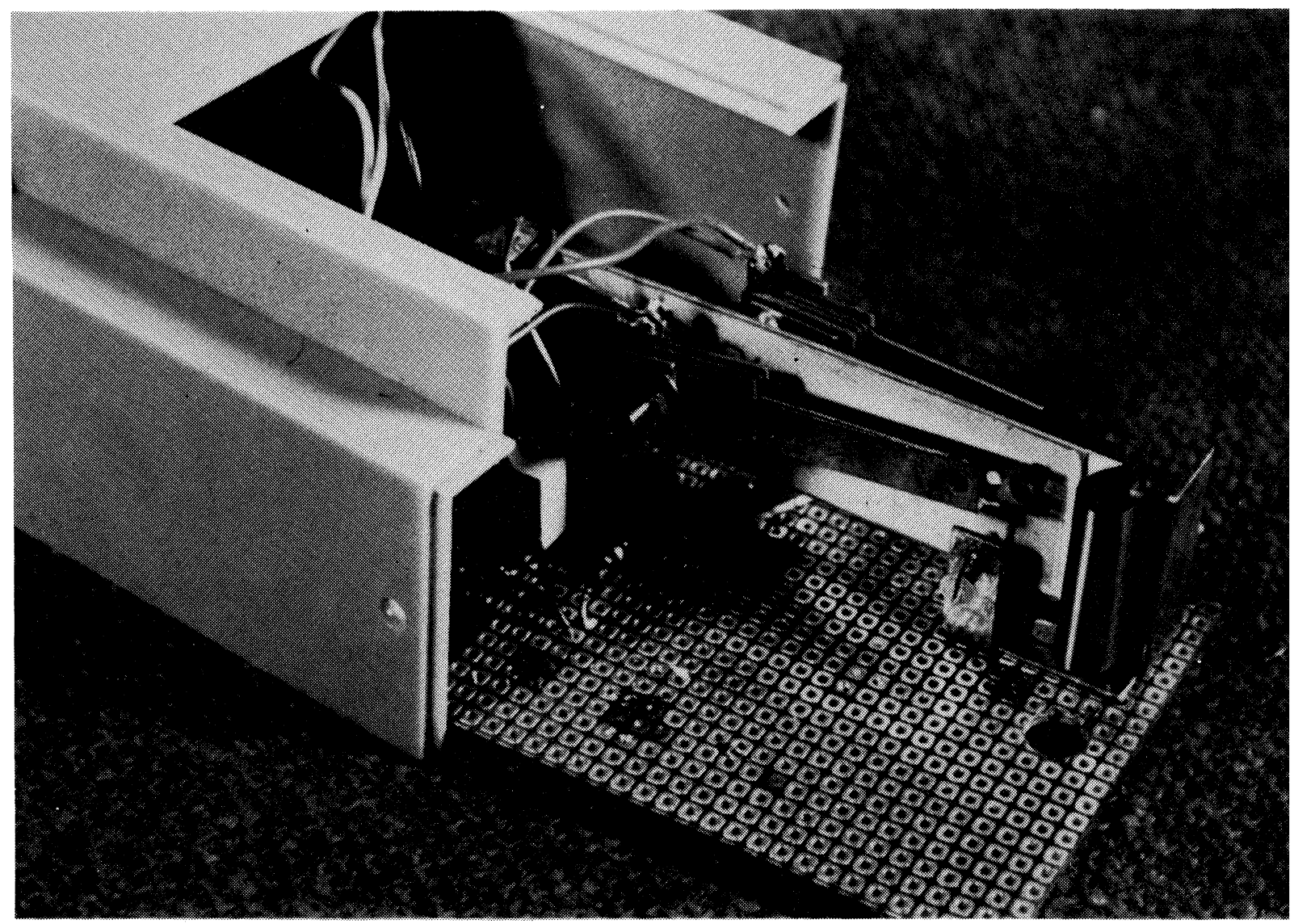

FIGURE 10 Delayed action relay test device (approximately life size) 
experimentally, and found to be in fairly good agreement with theory. Type $B$ is a simple bending strip, type $\mathrm{C}$ a similar element with stiffening fins to test the efficiency of transverse clamping, and type F, a highly efficient bender exhibiting both transverse clamping and the suppression of inactive bending modes, which was realized by using a transversly slotted wedge-shaped metal strip.

As an example numerical relations for the non-load deflection and the zero deflection force of a type B element, consisting of piezomaterial 1 and the alloy Vacon 70 will be given. For this composition $s_{1} / s_{2}=6$ is valid and Figure $5 \mathrm{~b}$ gives maximum energy for $t_{2} / t_{1}=0.70$. Under these conditions a non-load deflection of

$$
x=0.56 \frac{l^{2}}{t_{1}^{2}} d_{31} U
$$

and a zero deflection force of

$$
F=0.75 \frac{t_{1} \cdot w}{l} \cdot \frac{d_{31}}{s_{11}^{E}} U
$$

results.

\subsection{Delayed Action Relay Test Device}

Figure 10 shows a test device consisting of a type B bending element acting on two relay contacts. An Omega-spring is used for stiffness compensation and to give snap action. Figure 11 gives a schematic plot of the deflection-dependent force acting on the free end of an element of the type shown in Figure 7. Slope $F_{1}$ represents the elastic force of the bending element, superimposed on which is the force of the

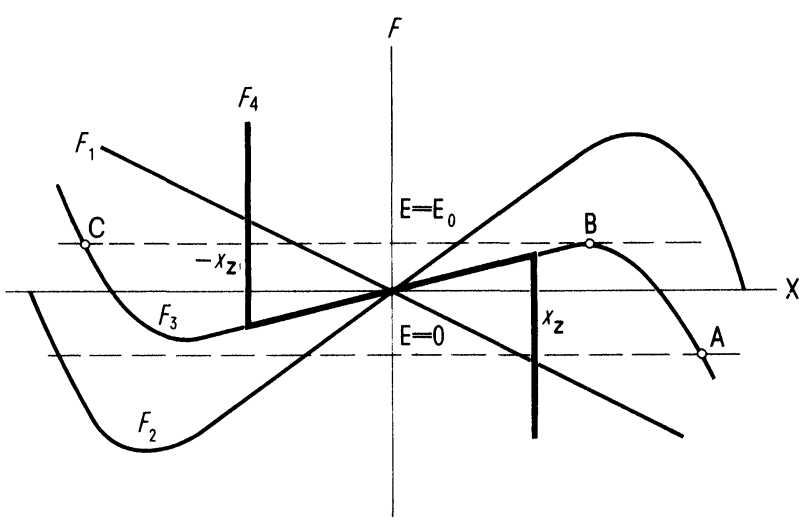

FIGURE 11 Force against deflection for a bending element with stiffness compensation (refer to Figure 7)

Omega-spring (slope $F_{2}$ ) resulting in slope $F_{3}$. Shifting the bearing point $P$ (Figure 7) in the negative $x$ direction produces a mechanical bias, shifting the $x$ axis downward in Figure 11. At zero voltage $(E=0)$, point $\mathrm{A}$ is the only stable position. Application of voltage corresponds to shifting the $x$ axis upward, and so displacing the stable position in the direction of $\mathrm{B}$. When point $\mathrm{B}$ is reached $\left(E=E_{0}\right)$, the position becomes unstable and the element snaps over to point $\mathrm{C}$. Before reaching point $\mathrm{B}$, the element is very sensitive to external vibrations, a drawback which can be overcome by limiting the deflection at $x_{l}$ and $-x_{l}$ obtaining slope $F_{4}$.

A special advantage of the piezoelectric relay is its minimal power drain. No holding power is required and power is used only during switching. This special feature is utilized in a simple time relay circuit. After switching, the element is slowly discharged via a large resistor and resets when it reaches a certain critical voltage. The snap function is very important in this application because slow contact opening must be avoided.

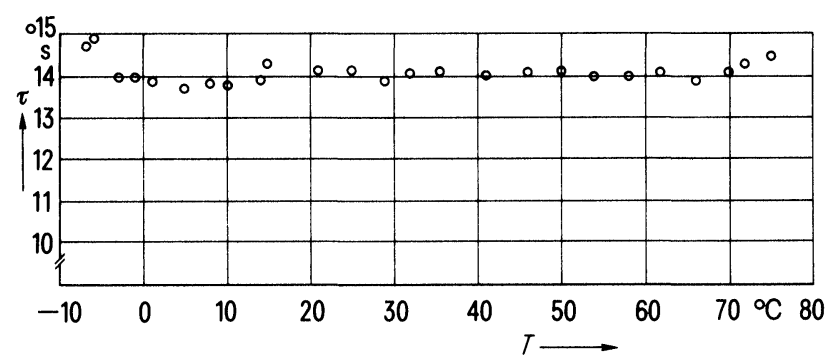

FIGURE 12 Delayed action relay test device; temperature dependence of the delay time

Figure 12 shows the temperature dependence of the delay time, which over the range of $-5^{\circ} \mathrm{C}$ to $+60^{\circ} \mathrm{C}$ is found to be within $\pm 2.5 \%$. The main properties of our test devices are listed in Table IV.

TABLE IV

Properties of the delayed action relay test device

Dimensions

Operating voltage

Contact deflection

Contact pressure

Delay time

Discharge resistor

Shunt capacitor
$80 \mathrm{~mm} \times 20 \mathrm{~mm} \times 0.6 \mathrm{~mm}$ $250 \mathrm{~V}$ to $400 \mathrm{~V}$

$1.5 \mathrm{~mm}$

$0.2 \mathrm{~N}$

$0.1 \mathrm{~s}$ to $20 \mathrm{~s}$

$10 \mathrm{M} \Omega$

$1 \mu \mathrm{F}$ 


\section{CONCLUSIONS}

Compared with conventional magnetic relays, the piezoelectric relay features certain new aspects which may be summarized as follows:

a) There is no power drain and no heat generation in the holding position and no reset when the operating circuit is removed.

b) The absence of coils and cores allows a simple flat construction of low mass and short response time.

c) The electromechanical efficiency is increased with increasing electric field.

The latter property makes it necessary to use thin sheet ceramic elements even for medium voltage applications. The small ceramic bulk resulting from this geometry however limits the mechanical energy. In Figure 9 the mechanical energies of certain conventional magnetic relays are inserted. Assuming a ceramic thickness of $100 \mu \mathrm{m}$ and an area of $1 \mathrm{~cm}^{2}$ we arrive at a bulk of $0.01 \mathrm{~cm}^{3}$, which leads to a minimum voltage of $50 \mathrm{~V}$ to $60 \mathrm{~V}$ for a low-energy relay such as the "National RSD".

For higher energies higher voltage is necessary. As an example the data of the time relay test device are also noted in Figure 9.

In general we can state, that the application of piezoelectric relays should be of interest in the range of line or higher voltage for low and medium contact energy because it is difficult to fabricate small magnetic relays for high operating voltage. On the other hand there should be interest in the region of lower voltage and low contact energy like in telephone applications, where any heat production is undesired because of tight packing.

For real low voltage application like TTL supply or automobile technique the proposed concept is unsuitable. Possibly multilayer thin film elements may one day penetrate into this region. A prototype of a COSMOS compatible multilayer relay ${ }^{6}$ operating at $28 \mathrm{~V}$ was recently described by Y Square Associates Inc. in USA. The relay, consisting of two face to face bending elements, was said to yield $0.04 \mathrm{~N}$ to $0.08 \mathrm{~N}$ contact force at a deflection of a few mils.

\section{ACKNOWLEDGEMENTS}

The authors wish to thank W. Wersing and R. Dänel for experimental support. Especial thanks are also due to Dr. I. Lucas for making theoretical results available to us in manuscript form.

\section{REFERENCES}

1. H. Brauer, Internal Report LB 1-253 Siemens AG (1964).

2. H. Krautwald and H. Schedele: Deutsches Gebrauchsmuster 1951219.

3. H. Brauer and J. Mohaupt: Internal Report LB 1-363 Siemens AG (1966).

4. Proc. IRE: Standards of Piezoelectric Crystals (1958).

5. I. Lucas. Siemens Forschungs- und Entwicklungs-berichte 4, 373 (1975).

6. Electronic Design 20, p. 19, Sept 27, 1973.

\section{Appendix}

List of Symbols

$\alpha_{31}, \alpha_{33}$

$c_{11}, c_{33}$

$D_{1}, D_{2}, D_{3}$

$D$ (superscript)

$d_{31}, d_{33}$

$e_{31}, e_{33}, \bar{e}_{31}, \bar{e}_{33}$

$E_{1}, E_{2}, E_{3}$

$E$ (superscript)

$\epsilon_{33}$

$F$

$g_{31}, g_{33}$
Energy gain factor

Elastic stiffness constants

Electric displacement components

At constant electric displacement

Piezoelectric strain constants

Piezoelectric stress constants

Electric field strength components

At constant electric field strength

Dielectric permittivity

Mechanical force

Piezoelectric strain constants $h_{31}, h_{33}$

$k_{31}$

$k_{33}$

$l$

$\mu$

$Q$

$s_{11}, s_{33}$

$S_{1}, S_{2}, S_{3}$

$S$ (superscript)

$T_{1}, T_{2}, T_{3}$

$T$ (superscript)

$T$ (Fig. 12)

$t$

$t$ (subscript)
Piezoelectric stress constants

Transverse coupling factor

Longitudinal coupling factor

Length

Poisson's constant

Mechanical quality factor

Elastic compliance constants

Strain components

At constant strain

Stress components

At constant stress

Temperature

Thickness

Signifies transposed matrix elements 
$\tau \quad$ Delay time

$U \quad$ Voltage

$V_{31}, V_{33}, V_{\text {rel }}$ Mechanical energy density

$w \quad$ Width

$x, y$
Directions $\perp$ to permanent polarisation

\section{$x$ (Figure 7,}

Figure 11)

$z$ polarisation
Deflection
Directions II to permanent



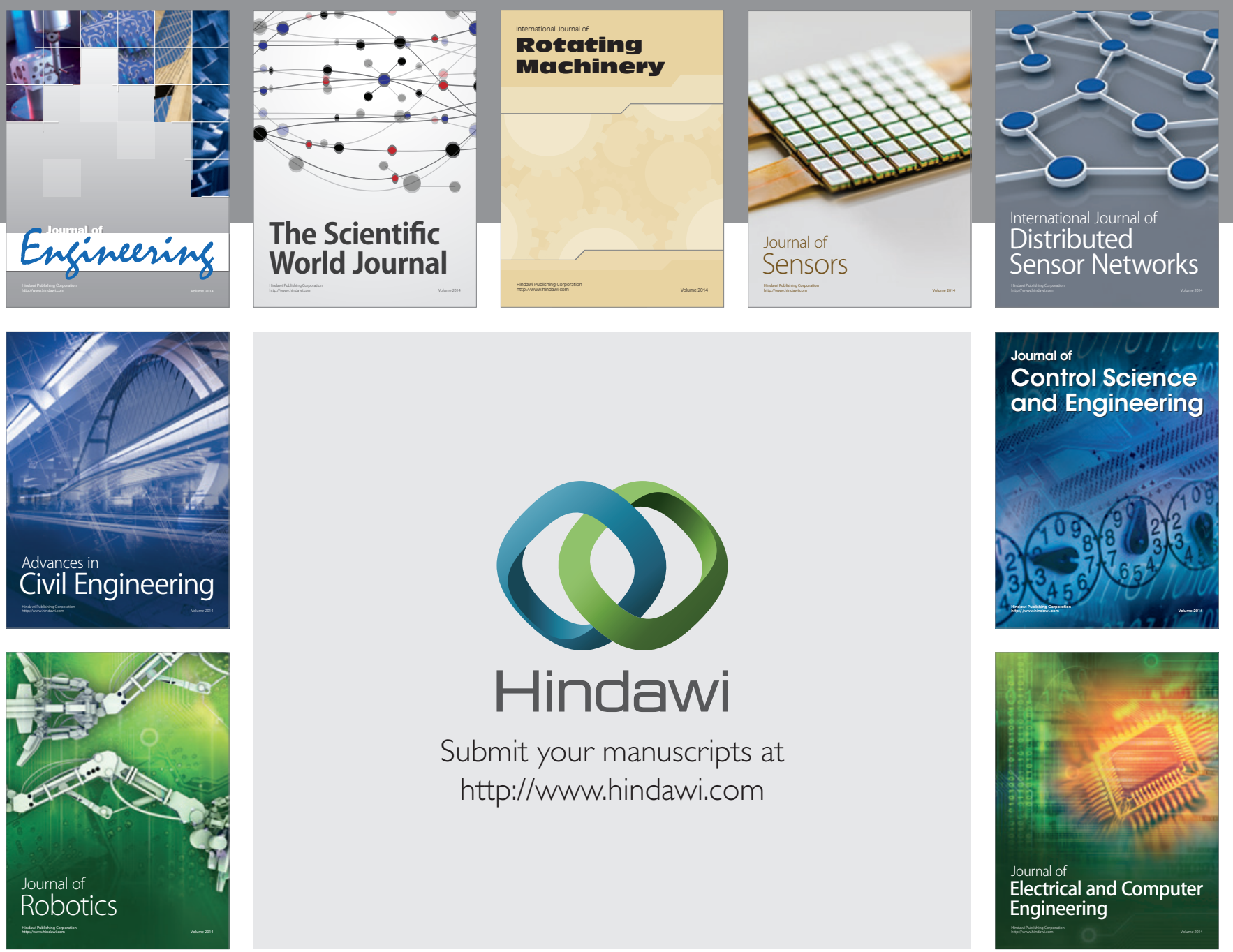

Submit your manuscripts at

http://www.hindawi.com
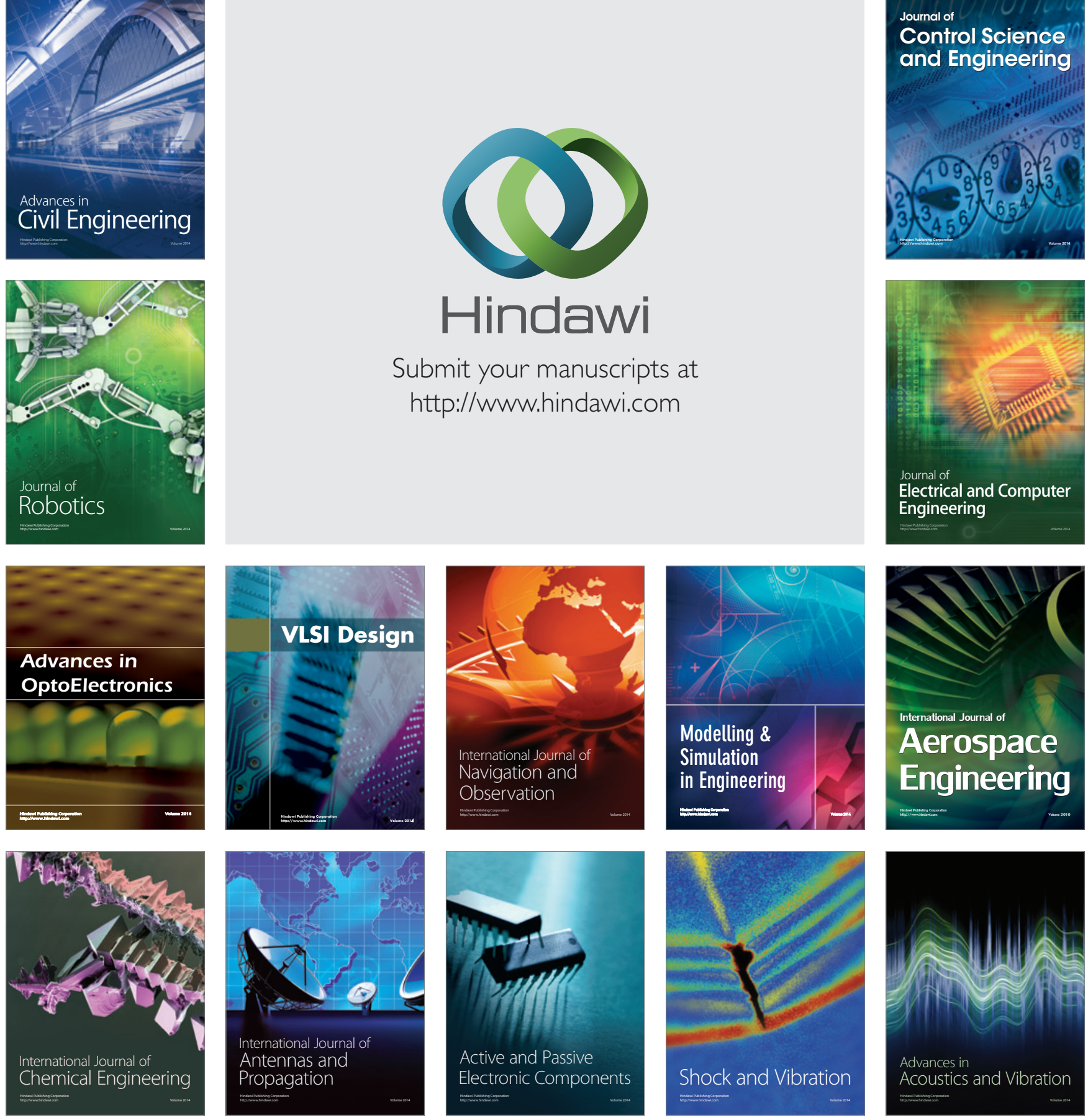